\title{
Locomotion of Stramonita haemastoma (Linnaeus) (Gastropoda, Muricidae) on a mixed shore of rocks and sand
}

\author{
Marcos G. Papp ${ }^{1}$ \\ Luiz F.L. Duarte ${ }^{1}$
}

\begin{abstract}
Mixed shores of rocks and sand are appropriate systems for the study of limitations that the isolation of rocks may impose for gastropods that typically inhabit rocky shores. We marked 52 Stramonita haemastoma (Linnaeus, 1767) snails on a mixed shore and found that 34 of them moved between rocks one to four times during 15 surveys in a period of 72 days. In the experiments, the snails moved on rock by continuous, direct, ditaxic, alternate undulations of the foot sole but on submerged sand they used slower arrhythmic discontinuous contractions of the foot sole. They switched between modes of locomotion in response to the type and topography of the substrate and possibly to water dynamics. In nature, snails moved between rocks forming aggregations where they oviposited. This may have masked other causes of movement, such as availability of prey. Most snails burrowed into the sand when the rocks became exposed during low tides. Further experiments are needed to explicitly address the possible causes of movements among rocks and burial.

KEY WORDS. Gastropoda, Muricidae, Stramonita, Thais, desiccation, locomotion, mixed shore, oyster drill, Brazil
\end{abstract}

Intertidal gastropods show a great diversity of locomotion modes and foot morphologies which are highly correlated with the type of substrate they inhabit (MILLER 1974a,b). Rocky shore gastropods usually have a small foot specialized for adhesion to the rock and many of them move using continuous undulations of the sole of the foot. Sandy shore gastropods, on the other hand, commonly have a large foot and move with the foot partially or totally burrowed, using discontinuous movements involving the whole foot (MILLER 1974b).

In mixed shores of rocks and sand, gastropods may have frequent contact with both kinds of substrate and their ability to cope with each substrate may become evident. TRUEMAN \& BROWN (1993) studied Burnupena catarrhacta (Gmelin, 1791) (Bucinidae), a rocky shore whelk common in the southwestern coast of South Africa, that uses pedal waves to crawl over the rocks. They found that it occurs in mixed shores and naturally crosses patches of sand using stepping movements of the foot sole, similar to those found in soft substrate gastropods (MILLER 1974a). They suggested that it might be a common phenomenon, as very few studies examined the locomotion of gastropods in mixed shores (TRUEMAN \& BROWN 1993).

1) Departamento de Zoologia, Instituto de Biologia, Universidade Estadual de Campinas. 13083-970 Campinas, São Paulo, Brasil. 
Stramonita haemastoma (Linnaeus, 1767), is a carnivorous rocky shore gastropod, commonly found in the intertidal area, that moves by direct, ditaxic, alternate undulations of the foot sole (GUNTER 1979). It feeds mainly on mussels, barnacles and oysters, but may also consume a large variety of other organisms. Sexes are separate and the individuals aggregate for spawning, when females lay eggs in capsules that are attached to the rock. The larvae are pelagic and reproduction takes place during the warmer months of the year (see BUTLER 1985 for a review on the biology of the species). Adults occur abundantly on the rocky shores of São Sebastião, in the state of São Paulo, southeastern Brazil (PETERSEN et al. 1986; MigotTo et al. 1993). We found it in mixed shores of rocks isolated by sand, where they occupied even small rocks ( $30 \mathrm{~cm}$ in diameter) that offered almost no prey and no shelter. We report the results of a study on the natural history of $S$. haemastoma in a mixed shore. We tried to determine how frequently movements among rocks happened and also compared the snails' locomotion on sand and on rocks, and looked for the most likely tidal conditions for the movements to occur. Finally, we searched for indications on the cause of the movements.

\section{MATERIALS AND METHODS}

We conducted this study at the Segredo beach ( $\left.23^{\circ} 49^{\prime} 39^{\prime \prime} \mathrm{S} ; 4^{\circ} 25^{\prime} 28^{\prime \prime} \mathrm{W}\right)$, in the area of the Centro de Biologia Marinha, Universidade de São Paulo, in São Sebastião county, state of São Paulo, Brazil. The area faces the São Sebastião channel and is sheltered from waves, with clear water and semidiurnal tides. The study site was a $48 \mathrm{~m}$ long mixed shore at the right edge of the beach, containing 38 rocks that were totally exposed during very low tides and submerged at about 70 $\mathrm{cm}$ depth during very high tides (details described by PETERSEN et al. 1986).

To determine the frequency of movements of S. haemastoma among rocks, we marked 52 individuals and recaptured them in the study site from 7 October 1994 to 18 December 1994. Marking and recapturing occurred during 15 low tides, at day and night time, concentrated in periods of spring tide, when the rocks were totally exposed at low water. We identified each animal individually using paper tags of $3 \times 4 \mathrm{~mm}$ glued to the external surface of the shells, and covered by a thin layer of glue to make them impermeable. When we captured an animal for the first time, we removed it from the rock manually to avoid injury, measured its total shell length, marked it and returned it to the same spot on the rock where it was captured, washing the spot with fresh marine water to facilitate reattachment. All marked individuals promptly adhered to the rock and did not move significantly until the first waves of the rising tide washed them, when they started crawling. Their behavior makes it unlikely that displacement by waves resulted from poor reattachment to the rock after marking. Recaptures were done visually, without removing the animals from the rocks.

Wave action and consequent water turbidity reduced the efficacy of direct observation as a method to determine if movements between rocks were voluntary or maybe caused by external factors, such as waves, dislodging the snails from the rocks. In case the movements were voluntary, it would be interesting to know how the animals move over sand and what are the tidal conditions under which the 
movements occur. We used three experiments to search for the answers to these questions.

We set up one experiment on the beach (experiment 1), where snails could stay on a small stone or cross sand to move to a large rock. We wanted to know if the snails would leave the stones actively, how they would move on sand, and if they would direct their movement towards the large rock. To facilitate observation, we selected conditions of high tide, small waves and calm water, and performed the experiment at $0.4 \mathrm{~m}$ depth. We allowed $S$. haemastoma individuals to adhere to small flat stones ( $5 \mathrm{~cm}$ in diameter) with no prey or crevices, and placed them radially around three isolated natural rocks $(n=12,16$ and 12$)$. Each stone had one snail and was positioned at $35 \mathrm{~cm}$ from the central rock and $25 \mathrm{~cm}$ from the nearest experimental small stone (Fig. 1). During one hour, we registered changes in the position, behavior, path and speed of each animal.

As $S$. haemastoma lives attached to rocks, one could expect that it would move more easily and therefore faster on rock than on sand. To test this assumption, we captured 20 adults near the study area and placed them individually in trays with seawater and sand, rock or a flat plastic board as substrate (experiment 2). Each animal was observed for 10 minutes and the speed of locomotion was recorded whenever an individual followed a strait path for more than $5 \mathrm{~cm}$. When sand was used as substrate, its surface was flat and the layer was $10 \mathrm{~cm}$ thick to prevent the feet of the animals from reaching the bottom of the tray. Plastic was used as substrate in addition to rock, to provide measurements on a smooth surface. During the tests, the water in the trays was still, to prevent circulation from altering the speed of the animals. The conditions of this experiment were repeated latter, using 10 individuals and only the sandy substrate, with an irregular profile. The goal was to observe if the slopes on the sand would interfere with the kind of movement used by the animals for locomotion. No measurements of speed were taken.

Another experiment assessed the tidal conditions at which movement would be more likely on the beach (experiment 3). We placed five S. haemastoma on sand at each of three heights of the shore: exposed sand, water fringe and $0.5 \mathrm{~m}$ deep and registered the movements of each animal during the next $10 \mathrm{~min}$, recording if the animal would burry the foot, if it would maintain its position or not, if it would move and what type of movement it would use for locomotion.

In search for evidence on the causes of movement of snails among rocks, we recorded the occurrence of reproductive aggregations and egg clutches during every mark and recapture event and also looked for a correlation between the amount of movement between rocks, and availability of prey on rocks. We determined the surface area of every rock in the study site by covering it with transparent film, marking its contour with a pen and measuring the area on the plastic sheet. We visually estimated coverage of sessile prey for barnacles Chthamalus bisinuatus Pilsbry, 1916 and Tetraclita stalactifera (Lamarck, 1818) mussels Brachidontes solisianus (Orbigny, 1846) and oysters Crassostrea rhizophorae (Guilding, 1828). We multiplied the estimated proportion of prey coverage by the surface of the rock, to obtain and estimate of the surface covered by prey on each rock. 


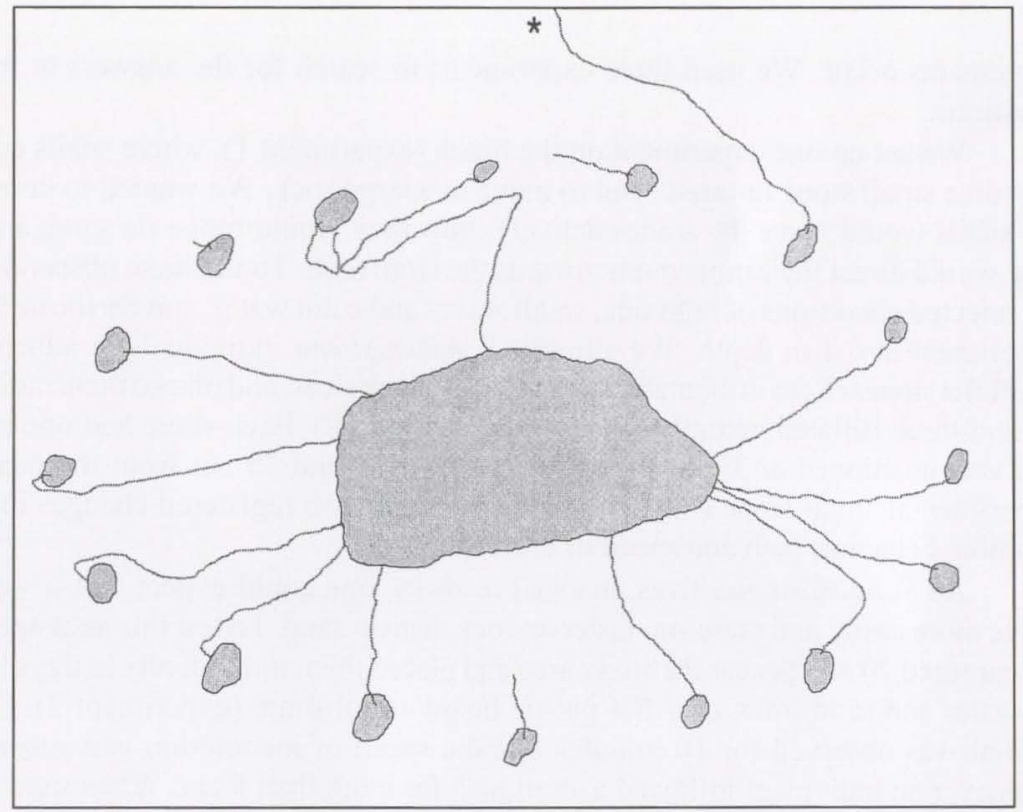

Fig. 1. Sketch of the movements of Stramonita haemastoma to one of the rocks used in experiment 2. The actual distance between neighboring stones was $25 \mathrm{~cm}$ and from any stone to the central rock it was $35 \mathrm{~cm}$. (*) An individual moved away from the central rock and reached a more distant rock during the experiment.

\section{RESULTS}

Movements of snails between rocks were common. We marked 52 individuals of S. haemastoma and found that 34 of them moved between rocks at least once, and some up to four times. We made 15 censuses and accumulated 202 recaptures, $24 \%$ of which indicated movement between rocks since the last capture of the individual (Fig. 2). Eight censuses were preceded by another census by one tidal cycle, and revealed that $2.1(\mathrm{SD}=1.4)$ of $15.6(\mathrm{SD}=5.7)$ snails moved between rocks. One census followed another two tidal cycles later and revealed that 7 of 19 snails moved. Four other censuses done after periods of $36.5(\mathrm{SD}=15.8)$ tidal cycles, revealed that $6(\mathrm{SD}=4.5)$ of $14.5(\mathrm{SD}=5.1)$ snails moved. Forty-seven observations represented new individuals that we did not mark. We observed a mean of 20.1 individuals $(\mathrm{n}=15, \mathrm{SD}=5.99)$ per survey, $13.5(\mathrm{n}=15, \mathrm{SD}=7.3)$ of which were already marked. The size of the snails that moved between rocks $(n=34$, mean $=$ $32.6 \mathrm{~mm}, \mathrm{SD}=4.0$ ) was not significantly different than the size of the ones that did not move $(\mathrm{n}=18$, mean $=30.4 \mathrm{~mm}, \mathrm{SD}=6.9)($ Man-Whitney $\mathrm{U}=242, p>0.05)$.

Stramonita haemastoma crawled on hard substrate using continuous direct, ditaxic, alternate undulations of the foot sole. On sand, it could move by the same means, or through a stepping movement made with the foot burrowed. In this second kind of movement (arrhythmic, discontinuous type 1, following MILLER 1974b) the shell and the posterior part of the foot remained static while the anterior part of the 


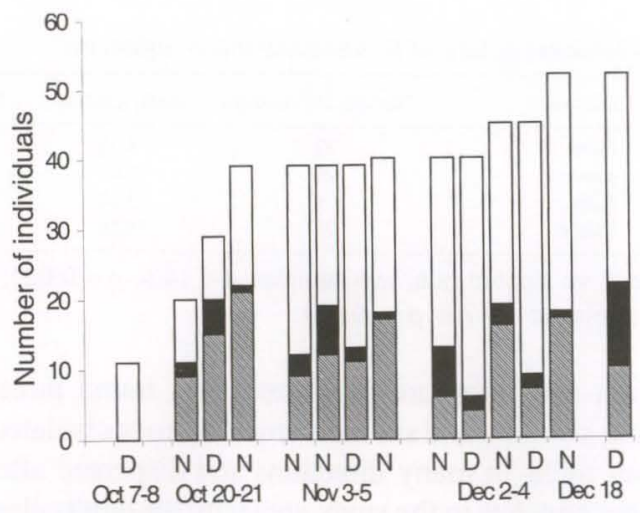

Fig. 2. Recapture and movements of marked $S$. haemastoma between rocks in a mixed shore. Abbreviations: $\mathrm{D}$, day; $\mathrm{N}$, night; refer to the time when the visual recapture surveys where done. Total bar height $=$ cumulative number of marked individuals; shaded $=$ animals that were found on the same rock where they were last recaptured; black = animals recaptured on a different rock.

foot advanced in the sand and anchored itself. After that, the foot was shortened, towing forward the shell and the posterior part of the foot. These two modes of locomotion were easily recognized by the extension of the foot in discontinuous mode, and by the pattern of movement of the shell (continuous or stepping).

Experiment 1 revealed $S$. haemastoma voluntarily leaving small rocks and crossing sand. From the 40 individuals initially placed on small stones, nine did not move and all the others moved on sand by discontinuous movements. Nineteen reached the closest natural rock, six moved in its direction but did not reach it during the experiment and six took other directions (we considered them in the direction of the rock when they were in the area of the triangle defined by the stone at the starting point and the two points where a line passing through the stone is tangent to the central rock).

When placed in a tray with a flat sandy bottom (experiment 2), all $S$. haemastoma burrowed the foot and started discontinuous movement. Gradually, some individuals switched to continuous movement and only two individuals persisted in discontinuous movement after 10 minutes. They moved faster on flat sand in continuous movement than in discontinuous movement (Tab. I). With continuous movement, they moved faster on PVC than on sand. When the experimental conditions were repeated, with uneven sandy bottom, the snails initially used the discontinuous mode of locomotion but after some minutes we observed animals switching to the continuous mode when moving downhill and back to the discontinuous mode when moving uphill.

From the 15 animals that we placed on the beach (experiment 3), none of the five on exposed sand moved, although three of them burrowed the foot. None of the five animals placed at the fringe of the water were able to stabilize their position on the sand, being washed away by the waves. All five individuals placed at $0.5 \mathrm{~m}$ burrowed their feet and started to move by discontinuous motion. 
Table I. Spontaneous underwater speed of S. haemastoma in aquarium.

\begin{tabular}{llccc}
\hline Type of movement & Substrate & Number of individuals & Mean (cm/min.) & Standart Devanation \\
\hline Discontinuous & Sand (1) & 22 & 4.11 & 1.20 \\
Continuous (2) & Sand (1) & 20 & 9.61 & 1.26 \\
Continuous & Rock & 4 & 9.38 & 1.04 \\
Continuous (2) & Plastic & 24 & 13.08 & 1.63 \\
\hline
\end{tabular}

(1) On sand, discontinuous vs. continuous: two samples, $t=14.5, p<0.001$; (2) Continuous movement on sand vs. on plastic: $t=7.8, p<-0.001$.

During the mark and recapture procedures, we found three reproductive aggregations containing six, nine and six individuals on rocks isolated by sand. The participants came from rocks in many directions and dispersed after ovipositing. We also found two other clutches in the study area with the adults already dispersed and did not find $S$. haemastoma aggregating in the study area without laying eggs, or snails laying eggs out of aggregates.

We observed S. haemastoma moving on the rocks only when submerged or being washed by waves. During nocturnal low tides, the animals remained motionless on the rocks whilst emersed until they started to be washed again. During diurnal low tides, they moved to crevices, sheltered areas with negative slope or, in most cases, crawled down the lateral surface of the rocks until they reached the sand, and stayed there partially or totally burrowed (up to $8 \mathrm{~cm}$ deep) until the rock was washed again. It was common to see the animals returning to higher areas on the rocks with the rising of the water level. We made eight nocturnal and seven diurnal surveys, and found more exposed (not burrowed) $S$. haemastoma at night (mean $=15.6, \mathrm{SD}$ $=5.68)$ than during the day (mean $=6.3, \mathrm{SD}=7.06)$ (two sample t-test, $t=2.84, p$ $=0.01)$ (Fig. 3).

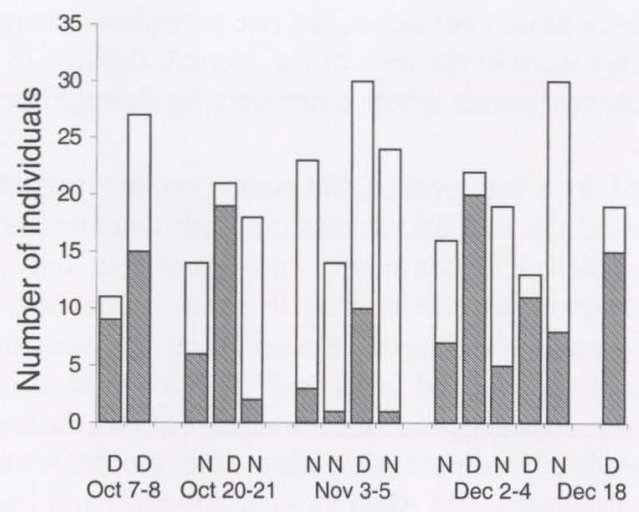

Fig. 3. Number of individuals of $S$. haemastoma found exposed on rocks (white) or burrowed in the sand (shaded) during spring low tides in a mixed shore.

During the study, we observed S. haemastoma feeding on barnacles $C$. bisinuatus and $T$. stalactifera, oysters $C$. rhizophorae, mussels $B$. solisianus and limpets Collisella subrugosa (Orbigny, 1846). Almost all the individuals that we 
found not burrowed on the rocks were active every high tide. The number of accumulated sightings of $S$. haemastoma on a rock was strongly correlated with the total amount of prey on it, given by the rock's exposed surface multiplied by its coverage by prey $(n=18, r=0.976, p<0.001)$. This indicates that the snails spend more time where there is food. In the movements between rocks, however, the destination rock did not present significantly more prey coverage (mean $=0.64 \mathrm{~m}^{2}$, $\mathrm{SD}=0.48)$ than the origin rock $\left(\right.$ mean $\left.=0.45 \mathrm{~m}^{2}, \mathrm{SD}=0.35\right)(\mathrm{n}=36$, Wilcoxon $\mathrm{T}$ $=234, p>0.5)$. We also analyzed 21 rocks but did not find a significant correlation between the amount of prey available on a rock and the number of snails that arrived to it $(r=0.003)$ or left it $(r=-0.216)$, with numbers of arrivals and departures weighted by the total number of records of snails on the rock.

\section{DISCUSSION}

The discontinuous movement of the foot of S. haemastoma, when on sand, is described for gastropods that typically inhabit sandy shores (MILLER 1974b; TRUEMAN \& BROWN 1992). This mode of locomotion is considered more efficient for burial than small pedal waves (MILLER 1974a; TRUEMAN \& BROWN 1992) and more effective to stabilize the animal on soft substrate. In our study, S. haemastoma buried the foot to move with discontinuous movements, but remained on the surface of the sand to move with continuous movements. The snails' behavior on sand, switching between modes of locomotion, might reflect a tradeoff between speed and stability. In experiment 2, the snails crawled on flat, stable sand more than twice as fast using continuous motion on the surface of the sand, than with the foot buried, using discontinuous motion, and the values were consistent with previously reported ones (MILLER 1974a; SMITH \& STICKLE 1982). The snails would, however, burry their foot and use discontinuous motion on the beach (experiments 1 and 3), where water circulation was high, and in the laboratory (experiment 2 ) initially and when faced with uphill slopes.

Although we did not observe any animal actually moving between rocks during the study, in the field (experiment 1 ) they actively left the small stones and crossed sand to reach the larger rock. BURKENROAD (1931) and BUTLER (1954) also reported $S$. haemastoma movements on soft muddy bottoms in Louisiana, and Florida. In experiment 1 , many animals reached the nearest natural rock, and several followed a direct path (see figure 1). In addition, S. haemastoma aggregated and spawned on isolated rocks that otherwise had few snails, and the individuals came from different directions. These observations suggest that the movements of $S$. haemastoma on sand might not be random, but we did not assess the existence of factors used in orientation. Olfaction is well developed in gastropods and it is used to detect prey, predators and conspecifics (KOHN 1961; HUGHES \& DUNKIN 1984; VADAS et al. 1994). BUTLER (1954) described the attraction of many individuals of $S$. haemastoma to trays with oysters placed on sandy bottom in 24 hours, and they are attracted to oysters killed by other snails (BUTLER 1985).

When placed on sand at different heights of the shore (experiment 3), $S$. haemastoma successfully moved only when submerged below the zone washed by waves. This condition occurred at the study site only during high tides and mainly 
during spring tides. The study encompassed 155 tidal cycles in which we detected 48 movements between rocks. At least 24 movements happened in periods of spring tide that accounted for only 10 tidal cycles (see figure 2, discount the first survey of each spring tide). On rocky shores, $S$. haemastoma explores the entire mussel zone for food and some of the upper barnacle zone (BUTLER 1979; MAGALHÃES \& COUTINHO 1995). In our study, the rocks that were in a higher position at the shore showed the highest abundance of prey and no S. haemastoma. It is possible that these rocks are washed long enough by waves during high tides to allow the growth of prey but they are not submerged deep enough or long enough to allow the $S$. haemastoma to cross the sand and exploit them.

Besides the restrictions discussed above, movements of $S$. haemastoma between rocks in the study site were common and possibly more frequent than detected by the surveys, because individuals could move more than once between two surveys. The formation of aggregations was an important cause of movement in our study and it may have masked patterns of prey exploration. Although we found more snails on rocks with higher availability of prey, the amount or direction of the movements was not correlated with the availability of prey on the rocks. Our failure to detect a correlation could be caused by preferences for specific prey types or sizes, which could render our estimate of total amount of prey inappropriate as a measure of resources on the rock. It is possible, however, that the snails are unable to sense the amount of prey available on the rocks nearby. They may move to any neighboring rock and spend more time on rocks where they find more prey.

Stramonita haemastoma is known to burrow in the mud around rocky shores during the coldest periods of the winter in North America (BUTLER 1954; RICHARDSON \& BROWN 1990). Our data indicates that on mixed shores, burial may happen daily during periods of enhanced tide variation. The fact that burial was more common in diurnal low tides than in nocturnal low tides indicates that it may be a defense against desiccation or overheating (MCMAHON 1992). It could also be a defense against predation, but it seems unlikely as no predators were observed attacking exposed snails during low tide.

This study revealed that $S$. haemastoma is capable of moving on sand using a previously unknown mode of locomotion for this species. It also showed that movements between rocks are common and happen mainly during spring tides, that vertical migration and burial occur during low tides and that oviposition occurs even on small isolated rocks. Further studies are needed to reveal the causes of movements between rocks and diary vertical migrations, and to determine how widespread is the ability to move on sand and burrow among gastropods that typically inhabit rocky shores.

ACKNOWLEDGEMENTS. We are grateful to C.A. de Magalhães for suggestions and to C.O.G. Papp, G.G. Rosenthal, M.J. Ryan, M. Tanaka and two anonymous reviewers for comments on the manuscript, and to the Centro de Biologia Marinha da USP (CEBIMar) for logistic support. 


\section{REFERENCES}

BurKenRoAD, M.D. 1931. Notes on the Louisiana conch, Thais haemastoma Linn., in its relation to the oyster, Ostrea virginica. Ecology 12: 656-664.

BUTLER, A.J. 1979. Relationships between height on the shore and size distributions in Thais spp. (Gastropoda: Muricidae). Jour. Exp. Mar. Biol. Ecol. 41: 163-194.

ButLer, P.A. 1954. The southern oyster drill. Proc. Natl. Shellfisheries Assoc. 44: 67-75.

- 1985. Synoptic review of the literature on the southern oyster drill Thais haemastoma floridana. NOAA Tech. Rep. NMFS 35: 1-9.

Gunter, G. 1979. Studies of the southern oyster borer, Thais haemastoma. Gulf Res. Rep. 6: 249-260.

Hughes, R.N. \& S. DE B. DunKIN. 1984. Behavioural components of prey selection by dogwhelks, Nucella lapillus (L.), feeding on mussels, Mytilus edulis (L.), in the laboratory. Jour. Exp. Mar. Biol. Ecol. 77: 45-68.

Korn, A.J. 1961. Chemoreception in gastropod molluscs. Amer. Zool. 1: 291-308.

MAGAlHÃES, C.A. DE \& R. COUTINHO. 1995. Distribution and zonation of three species of predatory gastropods: patterns and adaptations to wave impact in the rocky shore. Publ. Esp. Inst. Oceanogr. São Paulo 11: 123-131.

MCMAHON, R.F. 1992. Respiratory response to temperature and hypoxia in intertidal gastropods from the Texas coast of the Gulf of Mexico, p. 45-59. In: J. Grahame; P.J. Mill \& D.G. Reid (Eds). Proc. Third Intern. Symp. Littorinid Biol. Malacological Soc. London.

Migotto, A.E.; C.G. Tiago \& A.R.M. MagaliăES. 1993. Malacofana marinha da região costeira do Canal de São Sebastião, SP, Brasil: Gastropoda, Bivalvia, Polyplacophora e Scaphopoda. Bolm. Inst. Oceanogr. São Paulo 41: 13-27.

MilLER, S.L. 1974a. Adaptive design of locomotion and foot form in prosobranch gastropods. Jour. Exp. Mar. Biol. Ecol. 14: 99-156.

. 1974b. The classification, taxonomic distribution, and evolution of locomotor types among prosobranch gastropods. Proc. Malac. Soc. Lond. 41: 233-261.

Petersen, J.A.; J.P. Sutherland \& S. Ortega. 1986. Patch dynamics of mussel beds near São Sebastião (São Paulo), Brazil. Mar. Biol. 93: 389-394.

RICHARDSON, T.D. \& K.M. BROWN. 1990. Wave exposure and prey size selection in an intertidal predator. Jour. Exp. Mar. Biol. Ecol. 142: 105-120.

SMITH, D.J. \& W.B. STICKLE. 1982. Effects of temperature and salinity on chemoattraction and prey selection by the oyster drill, Thais haemastoma. Amer. Zool. 22: 853 .

Trueman, E.R. \& A.C. Brown. 1992. The burrowing habit of marine gastropods. Adv. Mar. Biol. 28: $389-431$.

-1993. Evolution of burrowing in gastropods: the behavior of the rocky-shore whelk Burnupena catarrhacta on sand. Jour. Moll. Stud. 59: 261-263

VADAS, R.L.S.R.; M.T. BurRows \& R.N. Hughes. 1994. Foraging strategies of dogwhelks, Nucella lapillus (L.): interacting effects of age, diet and chemical cues to the threat of predation. Oecologia 100: $439-450$.

Recebido em 28.X.1999; aceito em 05.IV.2001. 